\title{
Perbedaan Jumlah Perdarahan Saat Persalinan Pada Ibu Primigravida Yang Melakukan Dan Tidak Melakukan Senam Hamil Selama Kehamilan Trimester III
}

\author{
Febby Herayono ${ }^{1}$, Vaulinne Basyir ${ }^{2}$, Afriwardi $^{3}$
}

\begin{abstract}
Abstrak
Angka Kematian lbu (AKI) masih cukup tinggi di Indonesia, karena disebabkan oleh perdarahan, eklamsi dan infeksi. American College of Obstetricans and Gynecologist merekomendasikan senam selama kehamilan agar persalinan lancar dan mengurangi komplikasi saat persalinan. Tujuan penelitian adalah menentukan perbedaan antara jumlah perdarahan saat persalinan pada lbu primigravida yang melakukan dan tidak melakukan senam hamil selama kehamilan trimester III. Jenis penelitian adalah rancangan comparative study. Penelitian dilaksanakan di wilayah kerja Puskesmas Andalas dan Lubuk Buaya dari Oktober 2018 sampai Januari 2019. Jumlah sampel adalah 44 orang di bagi menjadi 2 kelompok, yaitu pertama 22 orang ibu yang melakukan senam hamil dan 22 orang ibu yang tidak melakukan senam hamil. Pengambilan sampel dengan consecutive sampling. Analisis data menggunakan system komputerisasi dengan uji independent $t$-test. Hasil penelitian didapatkan rerata jumlah perdarahan pada ibu yang senam hamil 489,18 cc dan pada ibu yang tidak senam hamil 501,86 cc. Tidak terdapat perbedaan jumlah perdarahan pada ibu yang melakukan dan tidak melakukan senam hamil dengan nilai $(p=0,786)$.
\end{abstract}

Kata kunci: jumlah perdarahan, senam hamil, primigravida

\begin{abstract}
The maternal mortality rate is high in Indonesia, that is caused by bleeding, eclampsia and infection. The American College of Obstetricans and Gynecologists recommend gymnastics during pregnancy so that labor is smooth and reduces complications during labor. The objective of the study was to determine the differences number of bleeding at delivery between primigravida who did pregnancy exercise and did not during the third trimester of pregnancy. The type of this research was a comparative study design. The study was conducted in the working area of Andalas and Lubuk Buaya Puskesmas from October 2018 until January 2019. The number of samples were forty four people, divided into two groups; twenty two mothers who did pregnancy exercises and twenty two mothers who did not do pregnancy exercises. Sampling by consecutive sampling. Data analysis using a computerized system with independent $t$-test. The average number of bleeding in mothers who exercise $489.18 \mathrm{cc}$ and mothers who are not pregnant exercise $501.86 \mathrm{cc}$. There is no difference in the number of bleeding $(p=0.786)$.
\end{abstract}

Keywords: amount of bleeding, pregnancy exercise, primigravida

\footnotetext{
Affiliasi penulis: 1. STIKes Ranah Minang Padang 2. Bagian Fetomaternal RSUD Rasyidin Padang 3. Bagian S3 Biomedik Fakultas Kedokteran Unviersitas Andalas Padang

Korespondensi: Febby Herayono, Email:

herayono_febby@ymail.com, Telp: 085263293436
}

\section{PENDAHULUAN}

Angka kematian maternal dan perinatal merupakan salah satu indikator keberhasilan pelayanan kesehatan. Angka Kematian lbu (AKI) di Indonesia masih cukup tinggi, untuk tahun 2015 yaitu AKI 305/100.00 kelahiran hidup. ${ }^{1}$ Salah satu penyebab tingginya $\mathrm{AKI}$ dan $\mathrm{AKB}$ di Indonesia adalah adanya komplikasi dan penyulit pada masa kehamilan dan persalinan. $^{2}$ Data penyebab terbanyak kematian ibu di Indonesia yaitu perdarahan $28 \%$, eklamsi $24 \%$, infeksi $11 \%$. Perdarahan merupakan penyebab utama yang 
menimbulkan kematian. ${ }^{3}$ Perdarahan postpartum adalah penyebab utama kematian ibu di Negara dengan penghasilan ekonomi yang rendah dan penyebab utama satu dari setiap empat kematian ibu di seluruh dunia. ${ }^{4}$

Salah satu upaya proses kehamilan dan persalinan dapat berjalan lancar dan tanpa ada komplikasi dan penyullit. Ibu hamil di anjurkan agar melaksanakan senam selama kehamilan sebagai upaya preventif agar kehamilan dan persalinan berjalan secara alami dan mengurangi resiko cidera akibat persalinan. ${ }^{5}$ Senam hamil di Indonesia merupakan bagian dalam pelayanan Antenatal Care (ANC) yang seharusnya dilaksanakan oleh setiap institusi pemberi pelayanan kesehatan ibu. ${ }^{6}$

Olahraga mampu meningkatkan kebugaran jasmani dan meningkatkan vaskularisasi darah sehingga dapat memperbaiki kontraksi otot. Beberapa penelitian juga menunjukkan bahwa kebugaran jasmani merupakan bagian essensial dari kesehatan ibu hamil, yang menghasilkan manfaat jangka panjang baik secara fisik maupun psikologis selama proses persalinan. ${ }^{7}$

Salah satu penyebab komplikasi dalam persalinan adalah kontraksi uterus yang tidak adekuat, serta serviks yang kaku pada primigravida, cemas menghadapi persalianan dan kelelahan. Komplikasi yang dapat ditimbulkan antara lain perdarahan, trauma jalan lahir dan asfiksia pada bayi baru lahir. ${ }^{8}$

Gerakan yang dapat mempengaruhi persalinan adalah latihan pernafasan, latihan mengejan, latihan penguatan, peregangan otot serta tekhnik relaksasi. Latihan ini dapat mempengaruhi power, passage dan passenger serta psikologis ibu pada saat persalinan, sehingga persalinan diharapkan dapar berjalan lancar. ${ }^{9}$

Penelitian ini bertujuan untuk menentukan perbedaan jumlah perdarahan saat persalinan pada ibu primigravida yang melakukan senam hamil dan tidak melakukan senam hamil selama trimester III.

\section{METODE}

Jenis penelitian ini adalah comparative study yaitu penelitian untuk membandingkan dua gejala atau lebih. Dalam penelitian ini akan membandingkan jumlah perdarahan saat persalinan pada lbu primigravida yang melakukan senam hamil dan tidak melakukan senam hamil selama kehamilan trimester III. Penelitian ini dilakukan pada kelas ibu hamil dan tempat Bidan Praktek Mandiri (BPM) yang ada di wilayah kerja puskesmas Andalas dan Puskesmas Lubuk Buaya Kota Padang pada bulan Oktober 2018 sampai dengan Januari 2019.

Jumlah sampel adalah 44 orang yang dibagi menjadi 2 kelompok, yaitu kelompok ibu yang melakukan senam hamil dan kelompok ibu yang tidak melakukan senam hamil selama kehamilan trimester III, jumlah sampel untuk masing-masing kelompok adalah sebanyak 22 orang. Pengambilan data dilakukan dengan melakukan observasi senam hamil dan penimbangan darah yang tertampung pada underpad pada saat persalinan.

Untuk mengetahui normalitas data dilakukan uji Shapiro-wilk dan perbedaan jumlah perdarahan pada kelompok yang senam dan tidak, dilakukan dengan uji statistik independent t-test.

\section{HASIL}

Penelitian ini dilaksanakan di kelas ibu hamil dan Bidan Praktik Mandiri yang ada wilayah kerja puskesmas Andalas dan Puskesmas Lubuk Buaya Kota Padang. Pada kelompok ibu yang mengikuti senam hamil, dilakukan observasi keteraturan ibu mengikuti senam hamil selama kehamilan trimester III. Penilaian jumlah perdarahan saat persalinan dilakukan dengan menggunakan timbangan dan menimbang underpad yang digunakan pada ibu saat persalinan.

Data lama persalinan dan jumlah pendarahan menggunakan uji normalitas Shapiro-wilk. Hasil uji normalitas menunjukkan data lama kala II dan jumlah perdarahan saat persalinan berdistribusi normal karena nilai $p>0,05$. Data yang berdistribusi normal dilanjutkan dengan uji statistik independent $t$-test untuk melihat perbedaan setiap kelompok.

Pada Tabel 1 terlihat hasil uji normalitas Shapiro-wilk untuk jumlah perdarahan saat persalinan pada ibu yang melakukan senam hamil dan tidak melakukan senam hamil selama trimester III. 
Tabel 1. Uji normalitas data jumlah perdarahan saat persalinan

\begin{tabular}{lcc}
\hline \multicolumn{1}{c}{ Variabel } & Rerata \pm SD & p \\
\hline $\begin{array}{l}\text { Jumlah Perdarahan } \\
\text { (cc) }\end{array}$ & $495,52 \pm 152,56$ & 0,286 \\
\hline
\end{tabular}

Pada Tabel 1 tampak hasil uji jumlah perdarahan saat persalinan pada ibu yang melakukan senam hamil dan tidak melakukan senam hamil terdistribusi normal dengan $p=0,286(p>0,05)$.

Tabel 2. Jumlah perdarahan saat persalinan pada ibu yang melakukan dan tidak melakukan senam hamil selama kehamilan trimester III

\begin{tabular}{lccc}
\hline \multicolumn{1}{c}{ Kelompok } & $\begin{array}{c}\text { Senam } \\
\text { Hamil }\end{array}$ & $\begin{array}{c}\text { Tidak Senam } \\
\text { Hamil }\end{array}$ & $\begin{array}{c}\text { Rerata } \pm \\
\text { SD }\end{array}$ \\
\hline Jumlah & 489,18 & 501,86 & $495,52 \pm$ \\
Perdarahan & & & 152,56 \\
(cc) & & & \\
\hline
\end{tabular}

Tabel 2 menggambarkan bahwa rerata jumlah perdarahan saat persalinan pada ibu yang melakukansenam hamil adalah 489,18 cc sedangkan rerata perdarahan pada ibu bersalin yang tidak melakukan senam hamil 501,86 cc.

Pada Tabel 3 menggambarkan perbedaan jumlah perdarahan ibu saat persalinan pada kelompok yang melakukan senam hamil dan tidak melakukan senam selama kehamilan trimester III.

Tabel 3. Perbedaan jumlah perdarahan saat persalinan pada ibu yang melakukan dan tidak melakukan senam hamil selama trimester III

\begin{tabular}{|c|c|c|c|}
\hline Variabel & $\begin{array}{c}\text { Senam } \\
\text { Hamil } \\
\text { Rerata } \pm \text { SD }\end{array}$ & $\begin{array}{c}\text { Tidak Senam } \\
\text { Hamil } \\
\text { Rerata } \pm S D\end{array}$ & $\mathbf{p}$ \\
\hline $\begin{array}{l}\text { Jumlah } \\
\text { Perdarahan } \\
\text { (cc) }\end{array}$ & $\begin{array}{c}489,18 \pm \\
156,6\end{array}$ & $\begin{array}{c}501,86 \pm \\
151,72\end{array}$ & 0,786 \\
\hline
\end{tabular}

Berdasarkan uji statisti independent t-test terlihat nilai $p>0,0,05$ maka dapat disimpulkan bahwa tidak terdapat perbedaan jumlah pendarahan saat persalinan pada ibu yang melakukan senam hamil dan tidak melakukan senam hamil selama kehamilan trimester III.

\section{PEMBAHASAN}

Hasil penelitian didapatkan bahwa rerata perdarahan pada ibu bersalin yang melakukan senam hamil adalah 489,18 cc, sedangkan rerata perdarahan pada ibu bersalin yang tidak melakukan senam hamil adalah 501,86 cc. Hasil uji statistik independent $t$-test terlihat nilai $p>0,05$ berarti tidak terdapat perbedaan antara jumlah perdarahanpadaibu bersalin yang melakukan senam hamil dan tidak melakukan senam hamil selama kehamilan trimester III.

Perdarahan post partum adalah kehilangan darah lebih dari $500 \mathrm{ml}$ dan berlanjut dan disertai dengan gejala lainnya. Perdarahan post partum dibagi menjadi perdarahan post partum primer yang terjadi dalam 24 jam pertama dan perdarahan post partum sekunder yang terjadi setelah 24 jam sampai dengan 6 minggu setelah persalinan. ${ }^{10}$

Semua persalinan akan selalu disertai dengan perdarahan. Perdarahan dapat terjadi sebelum, selama ataupun setelah proses persalinan. Suatu perdarahan akan dikatakan fisiologis apabila jumlah darah tidak melebihi 500 cc pada persalinan pervaginam. Perdarahan pasca persalinan adalah hilangnya darah lebih dari $500 \mathrm{cc}$ setelah anak lahir. ${ }^{11}$

Pada kehamilan cukup bulan, aliran darah ke uterus akan terjadi sebanyak 500-800 cc/menit. Jika uterus tidak berkontraksi dengan baik setelah kelahiran plasenta, maka ibu akan mengalami perdarahan sekitar 350-500 cc/menit dari bekas tempat melekatnya plasenta. Bila kontraksi uterus baik, maka myometrium akan menjepit pembuluh darah yang menyusup diantara myometrium. ${ }^{12}$

Setelah kelahiran bayi, terjadi rangkaian kontraksi uterus kedua yang memisahkan plasenta dari myometrium dan mengeluarkannya melalui vagina, terus berlanjut sehingga menyebabkan pembuluh darah uterus yang mengalir ketempat perlekatan plasenta menjadi terjepit dan mencegah perdarahan. $^{13}$

Olahraga selama hamil dapat menurunkan risiko persalinan prematur, karena selama melakukan latihan terdapat mekanisme penurunan stress oksidatif. Latihan ini juga dapat merangsang aktifitas myometrium sehingga kontraksi uterus menjadi maksimal dan membantu kelancaran persalinan. ${ }^{14}$ 
Olahraga selama kehamilan dengan frekuensi, durasi dan intensitas yang teratur di rekomendasikan bagi semua ibu hamil normal karena akan memberi manfaat terhadap ibu dan janin selama masa kehamilan, persalinan dan periode post partum. Latihan ini akan meningkatkan kebugaran kardiorespirasi, perbaikan inkontensia uri dan meredakan nyeri punggung, mengurangi tingkat stress, mengendalikan kenaikan berat badan selama hamil. Manfaat lain yaitu untuk meningkatkan kekuatan otot panggul, memberi kekuatan tubuh secara keseluruhan yang dapat membantu dalam proses kelahiran dan persalinan. ${ }^{15}$

Penelitian yang dilakukan oleh Megasari tentang salah satu faktor penyebab perdarahan saat persalinan adalah ibu yang tidak melakukan kunjungan antenatal K4 yaitu 2 kali lebih berisiko mengalami perdarahan pasca persalinan dari pada ibu yang tidak melakukan kunjungan $\mathrm{K} 4$ dengan nilai OR 2.090 (Cl 95\% 1.002- 4.359). ${ }^{16}$

Ibu hamil yang tidak melakukan kunjungan antenatal beresiko mengalami perdarahan pasca persalinan dari pada ibu yang melakukan kunjungan antenatal karena pada saat kunjungan, ibu hamil akan mendapatkan pemeriksaan kehamilan. Apabila seorang ibu hamil tidak melakukan kunjungan antenatal maka ibu hamil tersebut tidak akan mengetahui perkembangan kehamilannya sehingga tidak bisa terdeteksi secara dini risiko saat melahirkan serta kurang mendapatkan informasi dan persiapan untuk menghadapi persalinan yang aman bagi ibu dan janin. $^{16}$

Banyak faktor yang dapat menyebabkan terjadinya perdarahan selama persalinan, terdiri dari faktor langsung dan faktor tidak langsung (predisposisi). Faktor langsung adalah atonia uteri, tertinggalnya sisa plasenta, serta adanya robekan jalan lahir. Faktor predisposisi penyebab terjadinya perdarahan adalah umur ibu saat hamil, paritas, jarak kehamilan yang terlalu dekat, kadar HB ibu saat hamil, berat bayi, serta adanya riwayat perdarahan pada persalinan sebelumnya. ${ }^{10}$

Penyebab terjadinya perdarahan selama persalinan, diantaranya adalah atonia uteri yaitu kondisi myometrium yang tidak berkontraksi, adanya robekan jalan lahir yang dapat terjadi saat kepala dan bahu bayi dilahirkan, serta retensio plasenta atau kondisi tertahan nya plasenta hingga waktu 30 menit setelah bayi lahir. ${ }^{13}$

Hasil penelitian ini tidak terdapat perbedaan antara jumlah perdarahan saat persalinan pada ibu primigravida yang melakukan senam hamil dan tidak melakukan senam hamil selama kehamilan trimester III. Perdarahan yang dinilai pada penelitian ini adalah perdarahan saat persalinan yaitu pengeluaran darah saat persalinan yang dimulai ketika pembukaan sudah lengkap sampai dengan 2 jam setelah plasenta lahir.

Senam hamil bukan merupakan faktor langsung penyebab terjadinya perdarahan, namun merupakan suatu usaha yang dapat dilakukan untuk mempersiapkan ibu dalam menghadapi persalinan, serta mencegah terjadinya komplikasi dan penyulit dalam proses persalinan. Salah satu komplikasi yang dapat terjadi saat persalinan adalah partus lama dan perdarahan.

\section{SIMPULAN}

Tidak terdapat perbedaan jumlah perdarahan saat persalinan pada ibu primigravida yang melakukan senam hamil dan tidak melakukan senam hamil selama kehamilan trimester III

\section{UCAPAN TERIMA KASIH}

Peneliti ingin mengucapkan terima kasih kepada responden, bidan pembina wilayah, intruktur senam hamil dan pimpinan puskesmas andalas dan puskesmas lubuk buaya kota padang.

\section{DAFTAR PUSTAKA}

1. Kementerian Kesehatan RI. Profil kesehatan Indonesia. Jakarta: Kementerian Kesehatan RI 2016.hlm.102-4.

2. Prawiroharjo S. IImu kebidanan dan penyakit kandungan. Jakarta: Yayasan Bina Sarwono Prawirohardjo; 2013.hlm.12-3.

3. Kementerian Kesehatan RI. Riset kesehatan dasar (Riskesdas) 2013. Jakarta: Kementerian Kesehatan RI; 2013.hlm.48.

4. Durmaz A, Komurcu N. Relationship between maternal characteristics and post partum hemorrhage: a meta-analysis study. The Journal of Nursing Research. 2017;00(0):1-11. 
5. Clapp JF. The effect of continuing regular exercise on the physiologyc adaptations to pregnancy oucome. The American Journal of Sport Medicine. 2005;24(6):28.

6. Departemen Kesehatan RI. Senam hamil: dilakukan setiap hari untuk memperlancar proses persalinan. Jakarta: Departemen Kesehatan RI; 2009.hlm.1-4.

7. Guyton AC, Hall JE. Buku ajar fisiologi kedokteran. Edisi ke-12. Penterjemah: Ermita I, Ibrahim I. Jakarta: Penerbit Buku Kedokteran EGC; 2014: 1088-9.

8. Saifuddin AB. IImu Kebidanan. Edisi ke-4. Jakarta: Bina Pustaka Sarwono Prawirohardjo;2014.hlm.7-8

9. Kabuhung IE, Yunita L, Rusmiati S. Hubungan senam hamil dengan persalinan pada ibu bersalin di wilayah kerja Puskesmas Tanta tahun 2016. Dinamika Kesehatan. 2017;8(1):11-8.

10. Canterbury District Health Board. Postpartum haemorrhage (PPH). Christhurch Women's Hospital: Maternity Guidelines; 2019.

11. Prawiroharjo S. IImu kebidanan dan penyakit kandungan. Jakarta: Yayasan Bina Sarwono Prawiroharjo; 2013.hlm.124-30.
12. Jaringan Nasional Pelatihan Klinik Kesehatan Reproduksi (JNPK-KR). Asuhan persalinan normal asuhan esensial bagi ibu bersalin dan bayi baru lahir serta penatalaksanaan komplikasi segera pasca persalinan dan nifas. Jakarta: JNPK-KR; 2017.hlm.24-6.

13. Sherwood L. Fisiologi Manusia Dari Sel Ke Sistem. Edisi 6.Penterjemah : Pendit UB, Yesdelita N. Jakarta : EGC; 2011. HIm 160-162

14. Barakat R, Pelaez M, Montejo R, Refoyo I, Coteron J. Exercise troughout pregnancy does not cause preterm delivery: a randomized, controlled trial. Journal of Physical Activity and Health. 2014;5: 1012-7.

15. Nascimento SL, Surita FG, Cecatti JG. Physical exercise during pragnancy: a systematic review. Departemen of Obstetrics and Gynecology. 2012; 24:1-2.

16. Megasari. Faktor-faktor yang berhubungan dengan kejadian perdarahan pasca persalinan di RSUD Arifin Achmad Propinsi Riau tahun 2009-2010. Jurnal Kesehatan Komunitas. 2013;2(2):72-7/ 